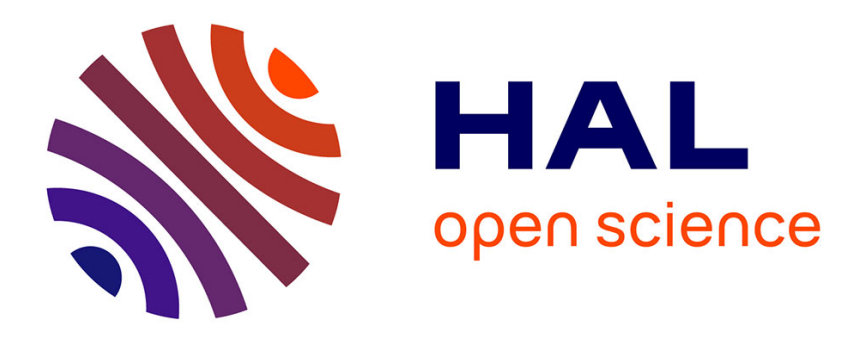

\title{
Binding specificity of the ectodomain of the parathyroid hormone receptor
}

Nils Drechsler, Julia Fröbel, Günther Jahreis, Mohanraj Gopalswamy, Jochen Balbach, Eva Bosse-Doenecke, Rainer Rudolph

\section{- To cite this version:}

Nils Drechsler, Julia Fröbel, Günther Jahreis, Mohanraj Gopalswamy, Jochen Balbach, et al.. Binding specificity of the ectodomain of the parathyroid hormone receptor. Biophysical Chemistry, 2011, 154 (2-3), pp.66. 10.1016/j.bpc.2011.01.002 . hal-00730301

\section{HAL Id: hal-00730301 https://hal.science/hal-00730301}

Submitted on 9 Sep 2012

HAL is a multi-disciplinary open access archive for the deposit and dissemination of scientific research documents, whether they are published or not. The documents may come from teaching and research institutions in France or abroad, or from public or private research centers.
L'archive ouverte pluridisciplinaire HAL, est destinée au dépôt et à la diffusion de documents scientifiques de niveau recherche, publiés ou non, émanant des établissements d'enseignement et de recherche français ou étrangers, des laboratoires publics ou privés. 


\section{Accepted Manuscript}

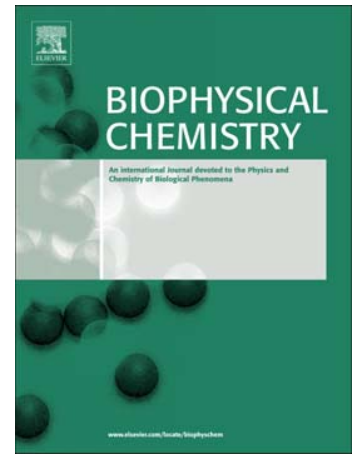

DOI:

S0301-4622(11)00003-2

Reference:

: 10.1016/j.bpc.2011.01.002

To appear in: Biophysical Chemistry

Received date: 12 October 2010

Revised date: 29 December 2010

Accepted date: $\quad 6$ January 2011

Please cite this article as: Nils Drechsler, Julia Fröbel, Günther Jahreis, Mohanraj Gopalswamy, Jochen Balbach, Eva Bosse-Doenecke, Rainer Rudolph, Binding specificity of the ectodomain of the parathyroid hormone receptor, Biophysical Chemistry (2011), doi: 10.1016/j.bpc.2011.01.002

This is a PDF file of an unedited manuscript that has been accepted for publication. As a service to our customers we are providing this early version of the manuscript. The manuscript will undergo copyediting, typesetting, and review of the resulting proof before it is published in its final form. Please note that during the production process errors may be discovered which could affect the content, and all legal disclaimers that apply to the journal pertain. 


\section{Binding specificity of the ectodomain of the parathyroid hormone receptor}

Nils Drechsler ${ }^{* a}$, Julia Fröbel ${ }^{* a, b}$, Günther Jahreis ${ }^{c}$, Mohanraj Gopalswamy ${ }^{\mathrm{d}}$, Jochen Balbach ${ }^{\mathrm{d}}$, Eva Bosse-Doenecke $^{\mathrm{a}} \&$ Rainer Rudolph ${ }^{\mathrm{a}}$

* ND and JF contributed equally to this work

Dedicated to Rainer Rudolph

Correspondence: E. Bosse-Doenecke, Institute of Biochemistry/ Biotechnology, Faculty of Science I, Martin-Luther-University Halle-Wittenberg, Kurt-Mothes-Str. 3, D-06120 Halle, Germany. Fax: +49 3455527 013, Tel: +49 3455524 889, E-mail: eva.bosse-doenecke@biochemtech.uni-halle.de

${ }^{\text {a }}$ Institute of Biochemistry/ Biotechnology, Faculty of Science I, Martin-Luther-University HalleWittenberg, Kurt-Mothes-Str. 3, D-06120 Halle, Germany

nils.drechsler@biochemtech.uni-halle.de

eva.bosse-doenecke@biochemtech.uni-halle.de

${ }^{\mathrm{b}}$ present address: Institute of Biochemistry/ Molecular Biology, Albert-Ludwigs-University Freiburg, Stefan-Meier-Straße 17, D-79104 Freiburg, Germany

julia.froebel@biochemie.uni-freiburg.de

${ }^{c}$ The Max Planck Research Unit "Enzymology of Protein Folding”, Weinbergweg 22, D-06120 Halle, Germany

jahreis@enzyme-halle.mpg.de

${ }^{\mathrm{d}}$ Institute of Physics, Biophysics group, Martin-Luther-University Halle-Wittenberg, Betty-HeimannStr. 7, D-06120 Halle, Germany 
mohanraj.gopalswamy@physik.uni-halle.de

jochen.balbach@physik.uni-halle.de

\begin{abstract}
Abbreviations
Ibs, inclusion bodies; IMAC, immobilized metal ion affinity chromatography; PTH1R, parathyroid hormone receptor; GPCR, G protein-coupled receptor
\end{abstract}

\title{
1. Introduction
}

The human parathyroid hormone receptor 1 (hPTH1R) is characterized by a large extracellular Nterminal domain and seven transmembrane spanning helices and belongs to the class B or secretin family of G protein-coupled receptors (GPCRs). According to the nomenclature, receptors of this superfamily control basic cellular processes and are specifically activated by peptide hormones including glucagon, glucagon-like peptide 1 (GLP-1R) [1-3], glucose-dependent insulinotropic polypeptide (GIPR) [4] and parathyroid hormone (PTH1R). Their N-terminal domains are stabilized by three highly conserved disulfide bonds. Ligand binding induces a conformational change in the receptor either resulting in the activation of adenylate cyclase or phospholipase-C [5] via $\mathrm{G}$ protein binding and signaling. Parathyroid hormone (PTH) specifically binds to PTH1R and thereby regulates the blood calcium and phosphate levels [6]. PTH is also a potent agonist of PTH2R, a related receptor which shares about $50 \%$ sequence homology with PTH1R [7].

The peptide hormone is secreted by parathyroid glands whenever the calcium levels in the blood are reduced or blood phosphate concentrations are increased [8]. Due to its involvement in diseases like osteoporosis and malignancy associated hypercalcemia [9], PTH represents a valuable therapeutic tool. A synthetic PTH 1-34 variant is used to treat osteoporosis by decelerating the rate of bone loss [10;11]. To use PTH as a drug, it is important to achieve comprehensive knowledge about its interaction with the cognate $G$ protein-coupled receptor.

In addition to the molecular structure of the ligand bound complex it is of great pharmaceutical interest to understand the role of individual residues involved in the ligand-receptor interaction [12;13]. This 
facilitates the development of improved agonists and antagonists for treatment of osteoporosis.

Moreover, these findings could help to elucidate the mechanism of receptor activation also for other members of this class of GPCRs and to develop respective therapies.

In the present study, we overexpressed the N-terminal domain of PTH1R (nPTH1R) in E. coli as inclusion bodies (Ibs). The nPTH1R aggregate was dissolved in guanidine hydrochloride and successfully refolded in vitro [14;15]. Full binding activity to the peptide fragment PTH (1-37) could be recovered as demonstrated by isothermal titration calorimetry (ITC). Further truncated variants of PTH and peptides with specific amino acid exchanges were designed to identify the functionally important amino acid residues. Critical positions were obtained from peptide library screens. In addition we recorded NMR data to analyse PTH (1-34) binding to its receptor ectodomain at a residueby-residue basis. We put our data into the context of the recently published crystal structure of the Nterminal domain of nPTH1R in complex with PTH (15-34) [12]. The NMR measurements show additional interaction sites at the N-terminus of PTH, which where not accessible in the crystal structure.

\section{Materials and Methods}

\subsection{Expression, purification and refolding of nPTH1R}

The nPTH1R was produced recombinantly, using the expression vector pET15b nPTH1R [15] and E. coli strain Rosetta pLys as a host. Fed batch fermentation was conducted in a 10 L Biostat ED bioreactor (B. Braun, Melsungen, Germany) with an initial volume of $6 \mathrm{~L}$ at $37^{\circ} \mathrm{C}$. Protein expression was induced at an optical density $\left(\mathrm{OD}_{600 \mathrm{~nm}}\right)$ of 55 by $1 \mathrm{mM}$ IPTG. For purification and refolding, a protocol according to Grauschopf et al. was used with minor modifications [15;16]. Briefly, cells were lysed and isolated inclusion bodies were stored at $-20{ }^{\circ} \mathrm{C}$. The receptor domain was enriched from solubilized Ibs by IMAC. For renaturation of nPTH1R a folding reactor (FairMenTech, Göttingen, Germany) at a constant temperature $\left(4{ }^{\circ} \mathrm{C}\right)$ was used. The denatured protein solution was added into a stirred refolding buffer. Four pulses with a maximum of $50 \mu \mathrm{g} / \mathrm{mL}$ protein were injected in intervals of $6 \mathrm{~h}$ into the vessel containing $2 \mathrm{~L}$ of $50 \mathrm{mM}$ Tris- $\mathrm{HCl}, \mathrm{pH} 8$ at $4{ }^{\circ} \mathrm{C}, 1 \mathrm{M} \mathrm{L}$-arginine, $1 \mathrm{mM}$ EDTA, 
$5 \mathrm{mM}$ GSH and $1 \mathrm{mM}$ GSSG. The incubation was continued for four days after the last pulse. Further purification was achieved via hydrophobic interaction chromatography using a phenyl sepharose 6 fast flow column (Pharmacia, Upsala, Schweden) and decreasing ammoniumsulphate concentrations in a linear gradient from $1 \mathrm{M}$ to $0 \mathrm{M}$ over $120 \mathrm{~mL}$. Size exclusion chromatography with a Superdex 75 prep grade column (Pharmacia, Upsala, Schweden) was used as final purification step. The protein yield was determined spectrophotometrically. Protein solutions were concentrated via an Amicon® Ultra - 15 device with 10.000 MWCO (Millipore, Billerica, USA).

\subsection{Peptide synthesis on continuous cellulose membrane support}

The peptide chains were synthesised on Whatman 50 paper $(140 \times 110 \mathrm{~mm})$ semi automatically using an Auto-Spot Robot APS 222 (Abimed GmbH, Langenfeld, Germany). Array design was performed using the software from Jerini Bio Tools GmbH (Berlin, Germany). For peptide synthesis, conventional Fmoc/ tBu chemistry was applied [17]. Prior to peptide chain synthesis, the cellulose membranes were modified with fluorenylmethoxycarbonyl (Fmoc) beta-alanine as first anchor residue [18]. Subsequently, the Fmoc protection groups were cleaved and $0.2 \mu \mathrm{L}$ of a $0.3 \mathrm{M}$ Fmocbeta-alanine-OPfp solution was used to configurate $17 \times 25$ spots with a beta-alanine-beta-alanine anchor and a diameter of $4 \mathrm{~mm}$ each. Excessive reactants were removed with dimethylformamide (DMF) and residual free amino functions on the membrane were acetylated with $5 \%$ acetanhydride and $2 \%$ diisopropylethylamine (DIPEA) in DMF. Again the Fmoc protection groups were cleaved and the membrane was stained with $0.01 \%$ bromophenol blue (BPB) in DMF to ensure the correct coupling reaction between the beta-alanines by indicating the unprotected N-terminal amino group. The peptides were synthesized from the C-terminal to the N-terminal position in a cyclic threefold coupling procedure with specific amino acids for the desired sequence. For that purpose $0.3 \mu \mathrm{L}$ of a 0.3 M solution of the amino acids with Fmoc protection groups dissolved in either $\mathrm{N}, \mathrm{N}$-dimethylformamide (DMF) or N-methyl-2-pyrrolidinone (NMP) were added stepwise to the membrane. After coupling the last amino acid, all Fmoc protection groups were cleaved with $20 \%$ piperidine in DMF and the membranes were acetylated with $5 \%$ acetanhydride in DMF and DIPEA. In a final step, the peptide side chain protection groups were removed by washing the membrane in 50 
$\%$ trifluoreacetic acid (TFA) in dichloromethane (DCM) and triisopropylsilane (TIS). Finally, the membranes were washed, dried and stored in sealed bags at $-20{ }^{\circ} \mathrm{C}$.

A typical spot synthesis yields $5-10 \mathrm{nM}$ equalling 6-12 $\mu \mathrm{g}$ for an average 10 mer peptide. Generally a purity of more than $70 \%$ for average 6-15 mers is achieved.

\subsection{Binding studies of cellulose bound peptides}

The peptide sequences were derived from the sequence of PTH. Membranes with 12 mer peptides covering PTH (1-84) overlapping by 11 amino acids were covalently attached at their C-terminal end to the beta-alanine anchor and used for first screen [19;20]. Libraries with shorter peptides and amino acid substitutions were produced as indicated in S 1 .

The spotted membranes were rinsed $3 \times 10$ min in water, $3 \times 10$ min in DMF and $3 \times 10$ min in water. Afterwards they were incubated in an $8 \mathrm{M}$ urea-buffer with $1 \%$ SDS (w/ v) and $0.15 \mathrm{mM}$ betamercaptoethanol for $20 \mathrm{~min}$ to denature the peptide chains. For renaturation of the peptides, the urea concentration was reduced to zero by steps of $1 \mathrm{M}$ with $20 \mathrm{mM}$ Tris-HCl, $\mathrm{pH}$ 7.5. Membranes were equilibrated at $20^{\circ} \mathrm{C}$ for 10 min with protein storage buffer $\left(50 \mathrm{mM}\right.$ Tris- $\mathrm{HCl}, \mathrm{pH} 8$ at $20{ }^{\circ} \mathrm{C}, 300 \mathrm{mM}$ $\left.\left(\mathrm{NH}_{4}\right)_{2} \mathrm{SO}_{4}\right)$ and incubated with $50 \mu \mathrm{M}$ nPTH1R in the same buffer supplemented with $0.05 \%$ Tween 20 overnight at $4{ }^{\circ} \mathrm{C}$ under gentle shaking. Subsequently, unspecifically bound nPTH1R was removed by washing the membranes with TBS buffer $\left(4{ }^{\circ} \mathrm{C}\right)$, and spot bound protein was electrotransferred with a semi dry blotter (SEMI-PHOR, Hoefer, Germany) onto pre-soaked nitrocellulose membranes (VWR international, Darmstadt, Germany). In this indirect method the nitrocellulose membranes were sandwiched between blotting paper, soaked with transfer buffer (25 mM Tris- $\mathrm{HCl}, \mathrm{pH} 7.4,0.15 \mathrm{mM}$ glycine, $0.05 \%$ Tween20 (v/ v) at $\left.4{ }^{\circ} \mathrm{C}\right)$. Electrotransfer was performed at a constant voltage of $40 \mathrm{~V}, 1 \mathrm{~mA} \mathrm{~cm}^{-2}, 100 \mathrm{~W}$ for 90 minutes. To reduce unspecific interactions, the membranes were blocked in TBT buffer with $5 \%$ milk powder. The transferred protein was detected with mouse anti PTH/PTHrP-receptor antibody (Santa Cruz, Heidelberg, Germany) and peroxidase conjugated goat anti mouse antibody Santa Cruz (Heidelberg, Germany). The final visualization was performed by using an enhanced chemiluminescence (ECL) system. 


\subsection{Synthesis of crystalline PTH peptides}

The PTH peptides were synthesized by solid-phase peptide synthesis with the robot Syro II (MultiSynTech, Witten, Germany) using 0.15 mmol pre-loaded Fmoc-amino acid-Wang resins (NovaBiochem, Läufelfingen, Switzerland). Synthesis was done by Fmoc strategy and standard protocol with Fmoc amino acids as building blocks, PyBOP (NovaBiochem) and N-methylmorpholine as coupling reagents in dimethylformamide. Piperidine (20\%)/ DMF was the standard cleavage cocktail used for Fmoc detachment. The resin was treated twice for 10 minutes. All couplings were performed using a four-fold excess of the Fmoc amino acid derivative PyBOP and N-methylmorpholine in DMF. A double coupling protocol was applied. After detachment of the peptides from the resins and site-chain deprotection with TFA/ DCM/ TIS/ thioanisol/ methylmercaptoacetamide/ water $(80 / 7.5 / 5 / 2.5 / 2.5 / 2.5)$ at room temperature for $2 \mathrm{~h}$, the crude peptides were precipitated by diethylether and purified by RP- HPLC on a Gilson 306 equipment with a SP 250/ 10 Nucleosil 100-7 C8 column (Macherey-Nagel, Düren, Germany) utilizing a water/ acetonitrile $(0.1 \%$ TFA) gradient. The purified peptides were lyophilized. The purity of the peptides was evaluated by analytical HPLC with a LiChroCART $^{\circledast}\left(\right.$ LiChrospher $^{\circledR}$ 100, RP8, $\left.5 \mu \mathrm{m}\right) 125$ x 4 mm column (Merck, Darmstadt, Germany). The purification was performed using water/ acetonitrile $(0.1 \%$ TFA) gradient $5-100 \%$ in $30 \mathrm{~min}$ and a flow rate of $1 \mathrm{~mL} / \mathrm{min}$ and the peptides were detected at $220 \mathrm{~nm}$.

\subsection{Isothermal titration calorimetry (ITC)}

For ITC measurements, a MicroCal ITC titration calorimeter (MicroCal. Inc., Northhampton, MA, USA) was used. All experiments were carried out in triplicate. Control experiments with PTH (1-37) were performed under the same conditions and their dilution enthalpies were subtracted from the one measured upon complex formation. Samples were extensively dialysed in $50 \mathrm{mM}$ Tris-HCl, $\mathrm{pH} 8$ at 4 ${ }^{\circ} \mathrm{C}, 100 \mathrm{mM}$ sodium chloride to achieve equal buffer conditions. The reaction cell (V $\left.1.4436 \mathrm{~mL}\right)$ contained a degassed solution of $30 \mu \mathrm{M}$ nPTH1R (10 times the $K_{\mathrm{D}}$ value) and twenty-eight $10 \mu \mathrm{L}$ aliquots of $300 \mu \mathrm{M}$ PTH peptide were injected to the protein solution at 5 min intervals via a computer-controlled $300 \mu \mathrm{L}$ microsyringe. The titration was performed at a stirring speed of $305 \mathrm{rpm}$ 
and at a constant temperature of $20{ }^{\circ} \mathrm{C}$. The peak areas produced by every injection were integrated and analysed with the ORIGIN software (MicroCal Software, Northhampton, MA, USA). The data were fitted with the one set of sites binding model. By the resulting fit of the data an observed apparent association constant $\left(K_{\mathrm{A}}\right)$, the enthalpy of binding $(\mathrm{H})$ and a binding stoichiometry $(\mathrm{N})$ were calculated.

\subsection{Nuclear magnetic resonance (NMR)}

Unlabeled and uniformly ${ }^{15} \mathrm{~N}$ labeled PTH (1-34) was recombinantly expressed and purified as a SUMO fusion protein according to a procedure described Bosse-Doenecke et al. [21;22]. All NMR measurements were acquired on a Bruker Avance II 600 spectrometer with $0.75 \mathrm{mM}$ samples of ${ }^{15} \mathrm{~N}-\mathrm{PTH}(1-34)$ and $1.42 \mathrm{mM}$ of nPTH1R for titration in $20 \mathrm{mM}$ sodium phosphate, $300 \mathrm{mM}$ sodium sulphate, pH 6 and $10 \% \mathrm{D}_{2} \mathrm{O}(\mathrm{v} / \mathrm{v})$ at $298.15 \mathrm{~K}$. The previously determined assignments of PTH (1-34) resonances were confirmed by $3 \mathrm{D}{ }^{15} \mathrm{~N}-\mathrm{NOESY}-\mathrm{HSQC}$ and $3 \mathrm{D}{ }^{15} \mathrm{~N}-\mathrm{TOCSY}-\mathrm{HSQC}$ [23;24]. NMR titration was performed by adding increasing amounts of unlabeled nPTH1R to the uniformly ${ }^{15} \mathrm{~N}$-labeled PTH (1-34) up to a molar ratio of 1:1.47. Perturbations of back bone ${ }^{1} \mathrm{H}$ and ${ }^{15} \mathrm{~N}$ chemical shifts upon nPTH1R binding were obtained from ${ }^{15} \mathrm{~N}$-TROSY-HSQC spectra. All spectra were processed by NMRPipe [25] and analysed using NMRView [26].

\section{Results}

\subsection{Binding studies of refolded nPTH1R on peptide libraries}

It has been reported that nPTH1R binds the truncated peptide PTH (1-34) with high affinity [26;27]. However, besides alanine und serine substitutions a systematic analysis of the influence of single amino acids of the peptide concerning affinity has not been investigated in detail. The role of residues 35 to 84 in receptor binding is also unclear so far. To address this issue, a peptide scanning library was created covering the sequence of PTH (1-84) and the reversed sequence (84-1) in 12mer peptides on a cellulose membrane with a shift of one amino acid per spot. After incubation of the membrane with 
nPTH1R, bound receptor was detected by western blot analysis. The assignment of the resulting membrane spots to the PTH sequences identified the key amino acids necessary for binding (Fig. 1A). The data show that the segment of PTH encompassing residues 12-32 is responsible for ectodomain binding. To analyze the interacting residues in more detail, the peptide scanning library was confined to the identified region starting with 10 spots with consecutive 12 mers and then 11 spots with 11 mers finishing with 18 spots with 4mers covering PTH within the sequence of amino acid 12 to 32 (Fig 1B). By this approach amino acid residues of PTH (12-32) that have a strong effect on the interaction with nPTH1R were identified and the sequence was further refined to the amino acids 20 to 26 of PTH to be the most important segment involved in binding to nPTH1R (S.1). Furthermore, this analysis showed that nPTH1R binding requires Arg20 and Trp23 in a certain distance [28]. This could be the reason for a slightly detectable binding to a stretch of the reversed sequence of PTH (34-1) where Arg60 and Trp62 again are within a similar distance as in the forward sequence (Fig 1A, D-F). In a next step we modified the PTH sequence by exchanging single residues to create peptides with varying affinities to the receptor ectodomain. For this, peptide libraries were generated in which every single amino acid position of PTH (20-26) was substituted against all 19 proteinogenic amino acids besides cysteine (Fig 1C). The densitometric analysis of the peptide library was quantified on two independent blots. The effects of the amino acid substitutions were differentiated between weaker or stronger binding to the nPTH1R and loss of binding (Fig 2). This revealed that substitutions against hydrophobic amino acids often lead to high affinity. For example, at position 20 (Arg) only substitution to Phe retained tight binding (Fig 2A). On the other hand, the exchange of Val21 against Trp or Tyr enhanced binding (Fig 2B). Substitution of a polar amino acid against an apolar residue did not significantly change the binding properties (Fig 2C). Generally, a quantitative analysis of receptor binding to peptide loaded membranes is limited. While the method allows the identification of important amino acids, it does not reveal exact binding affinities. Therefore, we used isothermal titration calorimetry with different peptide variants derived from the library screens to quantify the $\mathrm{PTH} / \mathrm{nPTH} 1 \mathrm{R}$ interaction.

\subsection{Binding studies of synthesized peptides using ITC}


To investigate and characterize the binding properties of selected variants in solution, isothermal titration calorimetry was applied. In addition to different peptide lengths we analyzed the impact of the exchange of certain residues which affected the binding properties to nPTH1R in the peptide library scans (Table 1). To compare the effects of the amino acid substitutions on receptor binding, all experiments were performed at fixed receptor and peptide concentrations and with at least two different nPTH1R preparations. Reference measurements with PTH (1-37) were performed (Fig 3A). The calculated $K_{\mathrm{D}}$-values for the reference were in good agreement with the reported $K_{\mathrm{D}}$ of $3.4 \mu \mathrm{M}$ [15]. First we investigated the optimal length of PTH necessary to determine low $K_{\mathrm{D}}$ values by ITC. The fragment PTH (13-31) still revealed a $K_{\mathrm{D}}$ value in the micromolar range (Table 1). This indicates the minimum length for a binding-competent peptide ligand in solution. As fragments went shorter, their $K_{\mathrm{D}}$ values increased until binding curves could no longer be derived from the ITC experiments (Table 1). A length of at least 18 residues was necessary for quantifiable affinity in solution, whereas with membrane bound fragments, binding could be detected with much shorter species. These are probably low affinity events not detectable with ITC (Fig 3B). We used PTH (1-34) as model peptide for substitution experiments except for our very first substitutions where we used PTH (1-37). According to the results from the peptide libraries, residue Trp23 was substituted against Ala or Ser to determine the impact of a hydrophobic residue at this position on the binding to nPTH1R. None of the peptides showed binding to the ectodomain of PTH1R. This indicates that Trp23 has a central role for binding. To confirm a hydrophobic based interaction at this position, Trp23 was exchanged against Phe. Indeed the binding capability was restored, albeit at lower affinity. This confirms the increase in binding to nPTH1R in the peptide library upon an increase in hydrophobicity. Further substitutions in the sequence of PTH (1-34) were tested: Arg20 was exchanged against Phe, Val21 against Tyr and Trp23 against Phe. Simultaneous substitutions at all three positions did not result in a functional peptide ligand indicating that not only hydrophobic residues as such are necessary. Rather specific amino acids at certain positions appear to be crucial to provide binding to nPTH1R. Based on these findings and the densitometric analysis of the peptide library scans (Fig 2B), a peptide was synthesized in which Val21 was substituted against Tyr. The affinity of this peptide to nPTH1R was three times 
lower than that of the wildtype (Fig 3C). The reverse sequence PTH (34-1) did not result in detectable binding.

\subsection{NMR titration experiments of nPTH1R with ${ }^{15} \mathrm{~N}-\mathrm{PTH}(1-34)$}

NMR spectroscopy is a well suited method to investigate conformational and dynamic changes upon protein-protein interactions in solution. Therefore, NMR titration experiments with ${ }^{15} \mathrm{~N}-\mathrm{PTH}(1-34)$ and unlabeled nPTH1R domain were performed. The applied ${ }^{15} \mathrm{~N}$-TROSY-HSQC experiment detects only backbone amides of ${ }^{15} \mathrm{~N}-\mathrm{PTH}$ (1-34) and suppresses all resonances of nPTH1R. A comparison of the spectra of ${ }^{15} \mathrm{~N}-\mathrm{PTH}(1-34)$ in the free (black in Fig 4) and bound state (red in Fig 4) revealed differences in the chemical shifts and the line width of the resonances of individual residues. About half of the resonances got broadened beyond detection limits possibly because of reaching the intermediate exchange regime in the bound state. These resonances belong to the C-terminal half of PTH (1-34) and comprise Glu19-Phe34 plus some of its N-terminal half. Residues Val2 - Gly12 plus Leu15 und Met18 show detectable resonances in the bound state without or with only small changes in the chemical shifts. The NMR spectrum of the bound state thus indicates that the C-terminal half of PTH (1-34) binds to nPTH1R whereas the N-terminal half remains solvent exposed and flexible enough to result in observable resonances. The general line broadening of the latter resonances is caused by the reduced overall tumbling of the complex compared to free PTH (1-34). This observation in solution corresponds nicely to recent structural work, where the C-terminal fragment PTH (15-34) could be crystallized in complex with nPTH1R [12].

\section{Discussion}

G Protein-coupled receptors are key players in the communication between the extracellular and intracellular space. Their dysfunction is involved in widespread and severe pathologic conditions like diabetes, osteoporosis and other metabolic disorders. To develop targeted therapies, detailed analysis of the function and structure of GPCRs is necessary. Because of the low natural abundance of this protein family, structural information was scarce until recently. Recombinant production brought a stunning progress in the field, although it took decades to solve for example the three dimensional 
structure of the beta-adrenergic receptor [29]. To circumvent the tedious expression and purification of a full length membrane protein, the option to restrict the investigation to ligand binding extracellular domains turned out to be successful for class B GPCRs [3;15;0]. Nevertheless development of suitable crystallization protocols and the availability of good quality crystals remain challenging. One aim in this context is, to obtain the functional conformation of the receptor and its respective ligand. Here we report a straightforward method to identify the key residues of a typical peptide ligand that are relevant for the interaction with a class B receptor, namely of PTH to its receptor ectodomain. With the help of the peptide spotting technique, we were able to identify an important receptor binding stretch within the natural hormone ligand PTH (1-84) comprising Lys13 to Val31, which could be traced down to a core region of $\operatorname{Arg} 20$ to Lys26. This is consistent with the results of an Ala scanning analysis described by Dean et al. [31] and of the recently published crystal structure of a PTH (15-34) peptide in complex with the PTH1R ectodomain [12]. Here, we extend these investigations by testing the whole PTH ligand for interactions. Moreover we quantified ligand binding in solution by ITC (Table 1). By a length scan analysis we could show that even 4 mers can bind as long as they possess the relevant amino acid composition including the essential Trp23 residue. The minimal length for binders with micromolar affinities in solution determined by ITC was however around 20 residues. This is also in agreement with the literature. The same length scan with a reverse control peptide revealed an interesting binding event on a hypothetical palindromic hydrophobic patch Arg20-Val21Glu22-Trp23-Leu24-Arg25-Lys26. Like in the forward peptide, the essential Trp23 with its adjacent Glu22 is surrounded by a neutral and a basic residue in the reversed version. Consequently, to a certain extent, some binding should occur. However, this interaction turned out to be very weak as no binding could be determined in ITC measurements with this variant.

From substitution experiments, we gained further insights into the relevant binding properties of different PTH positions. In the regions Met18-Asp30 and Arg20-Lys26 every single residue was exchanged against each proteinogenic amino acid except cysteine. From these experiments we could draw some general conclusions: Substitution by a hydrophobic amino acid shows a beneficial effect for nPTH1R binding. Insertion of Tyr, Trp, Phe or His led to stronger binding signals. This might be the result of additional hydrophobic (Tyr, Trp, Phe) or ionic (Arg, His) interactions and/ or optimized 
space filling by a bulky side chain. This observation is nicely supported by the data from the crystal structure showing the ligand closely packed into a hydrophobic groove of the receptor ectodomain. Part of these hydrophobic interactions are aromatic residues. E.g. Trp23 of PTH interacts with Leu41, Ile38 and Ile135 of the receptor and Tyr167 of the receptor with Val31 and Leu28 of PTH. On the other hand, the inversion or the insertion of a charge at different positions weakens the binding considerably. One important example is Arg20 which is deeply buried in the binding pocket according to the crystal structure of the complex. This polar residue seems to be indispensable for affinity and specifity of PTH. Furthermore, Arg20 is conserved among the PTH-family (TIP39 and PTHrP) and the residues that are in contact to Arg20 are conserved in PTH1R and PTH2R but not in most other class B GPCRs, suggesting that Arg20 is a key determinant or selectivity filter of ligand specificity for PTH and PTH-related ligands [8;32].

Even with the semi quantitative method of peptide library screening, the second essential player, Trp23, could be clearly identified. Each change at this position is detrimental for binding. On the other hand, a residue, which does not participate in the interaction to the receptor such as Glu22, can be changed without effecting nPTH1R binding. Besides the data concerning the critical length of a high affinity binder, additional confirmation of the high impact positions could be gained by ITC (Table 1). The exchange of Trp23 against residues such as Ala or Ser completely abolished detectable binding. Exchange against a more bulky and hydrophobic residue Phe retained some affinity but to a lower extent again indicating the relevance of Trp23 for the ligand properties. The three contact points Arg20, Val21 and Trp23 lost their function after exchange against other hydrophobic residues (Phe, Tyr, Phe). This indicates that affinity does not depend on a simple hydrophobic interaction. The control peptide was thus changed towards the PTHrP with a larger side chain on position 21 (Arg) and a Phe on position 23. Leaving Arg20 and Trp23 and only displacing Val21 by Tyr retained high affinity binding pointing towards a lower relevance of this residue for binding. The reversed peptide did not bind to the receptor in the micro molar range. All in all these test peptides show that nature optimized the fit of the ligand and that it is hard to improve by peptide engineering. Probably mutation at other apparently dispensable positions might ameliorate the affinity of PTH variants to the receptor. 
The NMR data from the titration of the nPTH1R to ${ }^{15} \mathrm{~N}-\mathrm{PTH}$ (1-34) confirmed in solution the PTH binding region 15-34 previously found in the crystal [12]. The comparison of the ${ }^{15} \mathrm{~N}-\mathrm{TROSY}-\mathrm{HSQC}$ spectrum of free and bound PTH (1-34) to nPTH1R showed a significant change in chemical shift upon binding for Gly12 that is missing in the PTH 15-34 fragment used for crystallization. Therefore, the binding site in PTH might further extend at least up to position 12. On the other hand, the first 10 residues at the N-terminus of PTH show no interaction with the ectodomain. This supports the model derived by Gardella and Jüppner [33], who claim on the basis of cross linking experiments, that these residues interact with extra cellular loops of the membrane bound full length receptor.

Regarding the C-terminal binding of PTH(1-34) we conclude, that the 15 fold difference in affinity between PTH(1-34) and PTH(1-31) is probably due to interactions of residues 32 to 34 detected in our NMR data. They constitute an additional coil in the alpha helical structure of the ligand placing Phe34 to the binding interface. Phe34 has also been identified as contact point in the crystal structure.

\section{Conclusion}

With this data we could verify, quantify and expand earlier findings for ligand binding of PTH1R, which might help to optimize PTH variants, which are already on the market to treat osteoporosis. Moreover, the combination of these methods might help to elucidate the amino acid positions crucial for binding of other interacting partners as well. It could be a useful alternative in those which withstand a full structural characterization including the chance to raise dynamic binding data. Furthermore, the combination of the methods applied here might be a platform for affinity optimization studies.

\section{Acknowledgement}

We thank Dr. Miroslav Malesevic for introduction into the peptide spotting technique and Dr. Angelika Schierhorn for mass analysis of synthesized peptides. We thank Prof. Dr. Elisabeth Schwarz for reading this manuscript. 
We acknowledge Maria Stammwitz and Stefan Augustin for excellent technical assistance.

This work was funded by the Deutsche Forschungsgemeinschaft (SFB610) and a grant of the excellence initiative of the state Saxony-Anhalt to JF and MG.

\section{Research Highlights}

Pin point GPCR ECD-binding competent stretch of parathyroid hormone PTH (1-84)

Narrow this stretch down to a core peptide region: PTH (20-26)

Identify single residues crucial for binding: Arg20, Trp23

Determine binding affinities of peptide variants in solution by ITC

Measure dynamic interaction in the PTH-nPTH1R complex by NMR at residue resolution

\section{References}

[1] K.E.Mayo, L.J.Miller, D.Bataille, S.Dalle, B.Goke, B.Thorens and D.J.Drucker, Pharmacological Reviews 55 (2003) 167-194.

[2] D.Donnelly, Febs Letters 409 (1997) 431-436.

[3] S.Runge, H.Thogersen, K.Madsen, J.Lau and R.Rudolph, Journal of Biological Chemistry 283 (2008) 11340-11347.

[4] D.J.Drucker, Diabetes Care 26 (2003) 2929-2940.

[5] A.B.AbouSamra, H.Jüppner, T.Force, M.W.Freeman, X.F.Kong, E.Schipani, P.Urena, J.Richards, J.V.Bonventre, J.T.Potts, H.M.Kronenberg and G.V.Segre, Proceedings of the National Academy of Sciences of the United States of America 89 (1992) 2732-2736.

[6] J.T.Potts, H.M.Kronenberg and M.Rosenblatt, Advances in Protein Chemistry 35 (1982) 323396.

[7] T.B.Usdin, C.Gruber and T.I.Bonner, Journal of Biological Chemistry 270 (1995) 15455-15458.

[8] T.B.Usdin, Trends in Pharmacological Sciences 21 (2000) 128-130.

[9] S.Kousteni and J.P.Bilezikian, Curr Osteoporos Rep 6 (2008) 72-76.

[10] E.Orwoll, W.Scheele, S.Paul, S.Adami, U.Syversen, A.Diez-Perez, J.M.Kaufman, A.Clancy and G.Gaich, Journal of Bone and Mineral Research 18 (2003) 9-17.

[11] L.E.Ashworth, Formulary 37 (2002) 129-+.

[12] A.A.Pioszak and H.E.Xu, Proceedings of the National Academy of Sciences of the United States of America 105 (2008) 5034-5039. 
[13] A.A.Pioszak, N.R.Parker, T.J.Gardella and H.E.Xu, Journal of Biological Chemistry (2009) M109.

[14] A.Bazarsuren, U.Grauschopf, M.Wozny, D.Reusch, E.Hoffmann, W.Schaefer, S.Panzner and R.Rudolph, Biophys.Chem. 96 (2002) 305-318.

[15] U.Grauschopf, H.Lilie, K.Honold, M.Wozny, D.Reusch, A.Esswein, W.Schäfer, K.P.Rücknagel and R.Rudolph, Biochemistry. 39 (2000) 8878-8887.

[16] R.Rudolph and H.Lilie, Nachrichten aus Chemie Technik und Laboratorium 45 (1997) 753-\&.

[17] R.Frank, Journal of Immunological Methods 267 (2002) 13-26.

[18] U.Reineke, A.Kramer and J.Schneider-Mergener, Combinatorial Chemistry in Biology 243 (1999) 23-36.

[19] D.F.Winkler and W.D.Campbell, Methods in Molecular Biology (2008) 47-70.

[20] G.B.Fields and R.L.Noble, International Journal of Peptide and Protein Research 35 (1990) 161214.

[21] C.Löw, U.Weininger, H.Lee, K.Schweimer, I.Neundorf, A.G.Beck-Sickinger, R.W.Pastor and J.Balbach, Biophysical Journal 95 (2008) 4315-4323.

[22] E.Bosse-Doenecke, U.Weininger, M.Gopalswamy, J.Balbach, S.M.Knudsen and R.Rudolph, Protein Expression and Purification 58 (2008) 114-121.

[23] M.Scian, M.Marin, M.Bellanda, L.Q.Tou, J.M.Alexander, M.Rosenblatt, M.Chorev, E.Peggion and S.Mammi, Biopolymers 84 (2006) 147-160.

[24] U.C.Marx, K.Adermann, P.Bayer, W.G.Forssmann and P.Rosch, Biochemical and Biophysical Research Communications 267 (2000) 213-220.

[25] F.Delaglio, S.Grzesiek, G.W.Vuister, G.Zhu, J.Pfeifer and A.Bax, Journal of Biomolecular NMR 6 (1995) 277-293.

[26] B.A.Johnson and R.A.Blevins, Journal of Biomolecular NMR 4 (1994) 603-614.

[27] G.V.Segre, M.Rosenblatt, B.L.Reiner, J.E.Mahaffey and J.T.Potts, Journal of Biological Chemistry 254 (1979) 6980-6986.

[28] T.J.Gardella, M.D.Luck, G.S.Jensen, T.B.Usdin and H.Jüppner, Journal of Biological Chemistry 271 (1996) 19888-19893.

[29] V.Cherezov, D.M.Rosenbaum, M.A.Hanson, S.G.F.Rasmussen, F.S.Thian, T.S.Kobilka, H.J.Choi, P.Kuhn, W.I.Weis, B.K.Kobilka and R.C.Stevens, Science 318 (2007) 1258-1265.

[30] C.Parthier, M.Kleinschmidt, P.Neumann, R.Rudolph, S.Manhart, D.Schlenzig, J.Fanghänel, J.U.Rahfeld, H.U.Demuth and M.T.Stubbs, Proceedings of the National Academy of Sciences of the United States of America 104 (2007) 13942-13947.

[31] T.Dean, A.Khatri, Z.Potetinova, G.E.Willick and T.J.Gardella, Journal of Biological Chemistry 281 (2006) 32485-32495.

[32] T.B.Usdin, S.R.J.Hoare, T.Wang, E.Mezey and J.A.Kowalak, Nature Neuroscience 2 (1999) 941-943. 
[33] T.J.Gardella and H.Jüppner, Trends Endocrinol.Metab. 12 (2001) 210-217. 
Tables

Table 1. Results from the PTH to nPTH1R binding monitores by isothermal titrations calorimetry.

The primary sequences of the respective PTH fragments and variants are indicated together with the gain in Gibbs free energy $(\Delta G)$ upon binding and the dissociation constant $\left(K_{\mathrm{D}}\right)$ assuming a $1: 1$ binding model.

\begin{tabular}{|c|c|c|c|}
\hline Name & Sequence & $\begin{array}{c}\Delta G \\
(\mathbf{k J} / \mathbf{m o l})\end{array}$ & $K_{\mathrm{D}}(\mu \mathrm{M})$ \\
\hline PTH 1-37 & SVSEIQLMHNLGKHLNSMERVEWLRKKLQDVHNFVAL & 30.0 & 4.5 \\
\hline PTH 1-31 & SVSEIQLMHNLGKHLNSMERVEWLRKKLQDV & 23.4 & 68 \\
\hline PTH 4-31 & EIQLMHNLGKHLNSMERVEWLRKKLQDV & 24.5 & 43 \\
\hline PTH 7-31 & LMHNLGKHLNSMERVEWLRKKLQDV & 22.1 & 117 \\
\hline PTH 10-31 & NLGKHLNSMERVEWLRKKLQDV & 24.5 & 44 \\
\hline PTH 13-31 & KHLNSMERVEWLRKKLQDV & 21.7 & 132 \\
\hline PTH 13-34 & KHLNSMERVEWLRKKLQDVHNF & 22.5 & 98 \\
\hline PTH 15-34 & LNSMERVEWLRKKLQDVHNF & - & no binding \\
\hline PTH 18-30 & MERVEWLRKKLQD & - & no binding \\
\hline $\begin{array}{l}\text { PTH 1-34 } \\
\text { W23S }\end{array}$ & SVSEIQLMHNLGKHLNSMERVE $\underline{\mathbf{S}}$ LRKKLQDVHNF & - & no binding \\
\hline $\begin{array}{l}\text { PTH 1-34 } \\
\text { W23A }\end{array}$ & SVSEIQLMHNLGKHLNSMERVE $\underline{\mathbf{A}}$ LRKKLQDVHNF & - & no binding \\
\hline PTH 34-1 & FNHVDQLKKRLWEVREMSNLHKGLNHMLQIESVS & - & no binding \\
\hline $\begin{array}{l}\text { PTH 1-34 } \\
\text { R20W, } \\
\text { V21F, } \\
\text { K26F }\end{array}$ & SVSEIQLMHNLGKHLNSME $\underline{\mathbf{W}} \underline{\mathbf{F}}$ EWLR $\underline{\mathbf{F}}$ KLQDVHNF & - & no binding \\
\hline $\begin{array}{l}\text { PTH 1-34 } \\
\text { W23F }\end{array}$ & SVSEIQLMHNLGKHLNSMERVE $\underline{\mathbf{F}}$ LRKKLQDVHNF & 25.4 & 30 \\
\hline $\begin{array}{l}\text { PTH 1-34 } \\
\text { V21Y }\end{array}$ & SVSEIQLMHNLGKHLNSMER $\underline{\mathbf{Y}}$ EWLRKKLQDVHNF & 27.1 & 15 \\
\hline
\end{tabular}


$\mathbf{A}$,
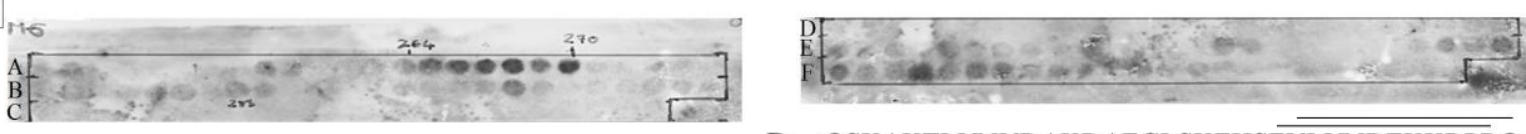

D QSKAKTLVNVDAKDAEGLSKEHSEVLVNDEKKRPRQ
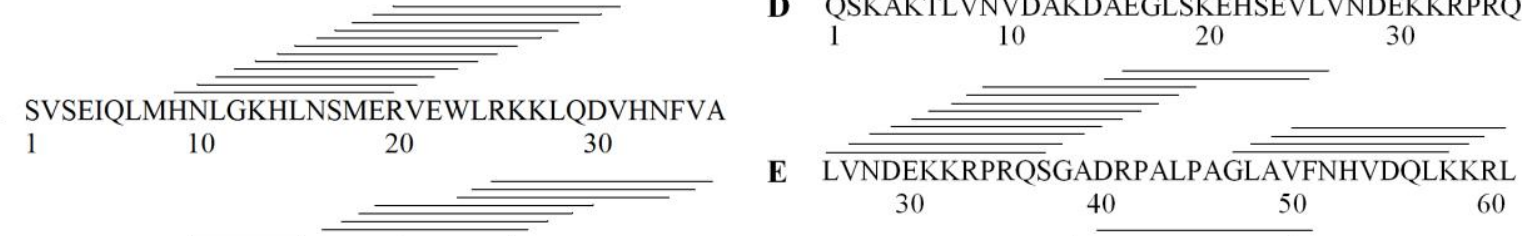

A SVSEIQLMHNLGKHLNSMERVEWLRKKLQDVHNFVA
10
20
30
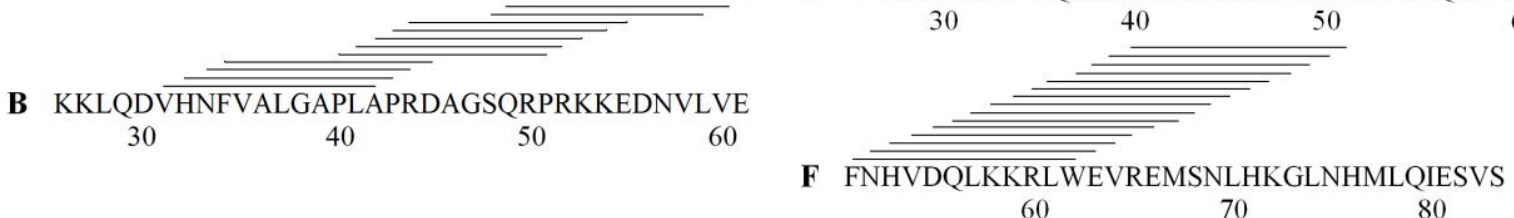

C PRKKEDNVLVESHEKSLGEADKADVNVLTKAKSQ

$$
60 \quad 70 \quad 80
$$

Figure 1a

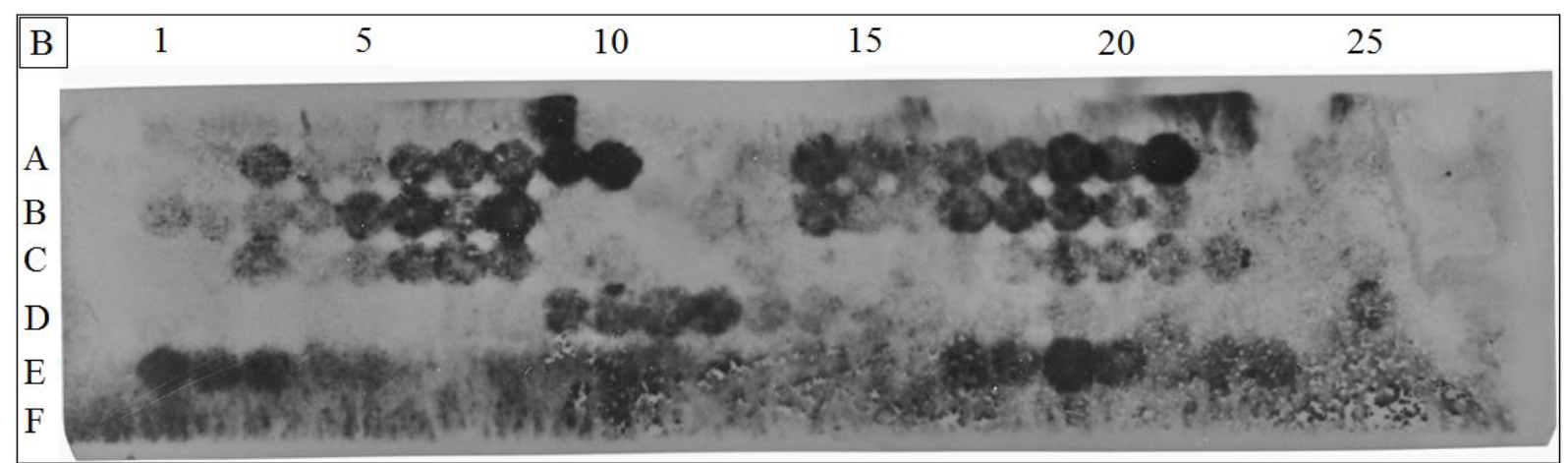

\section{Figure 1b}

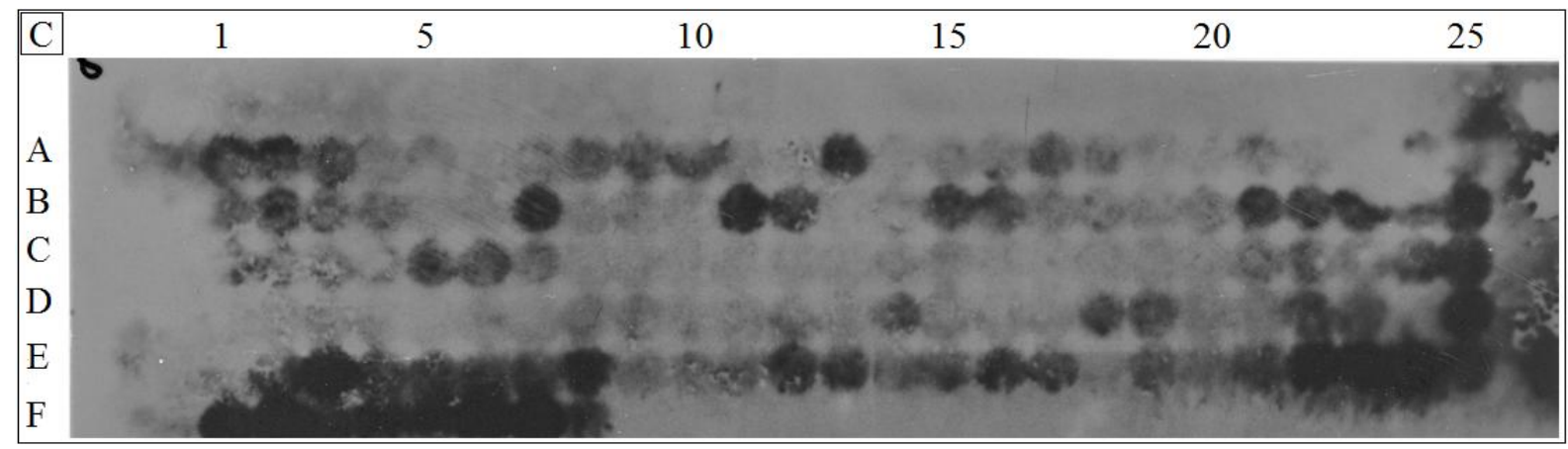

Figure 1c 

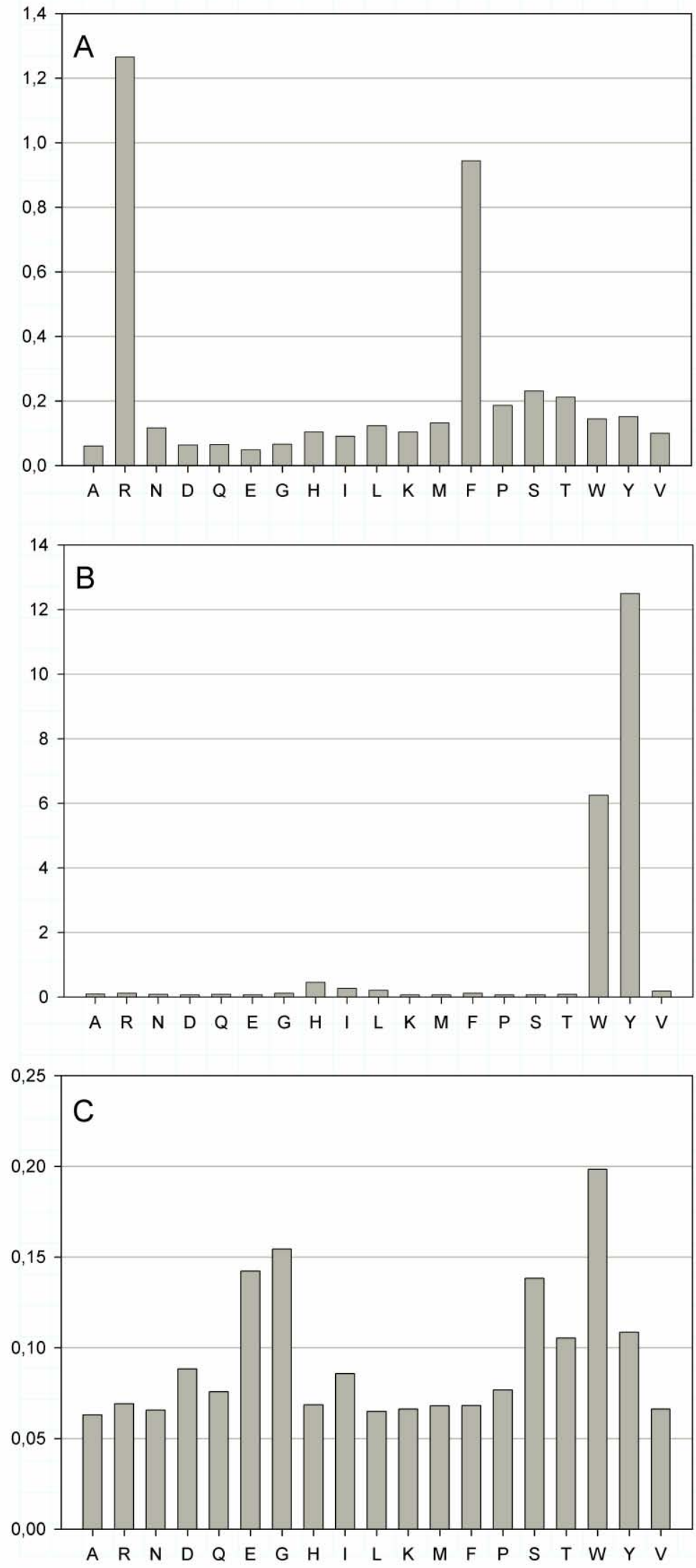

Figure 2 

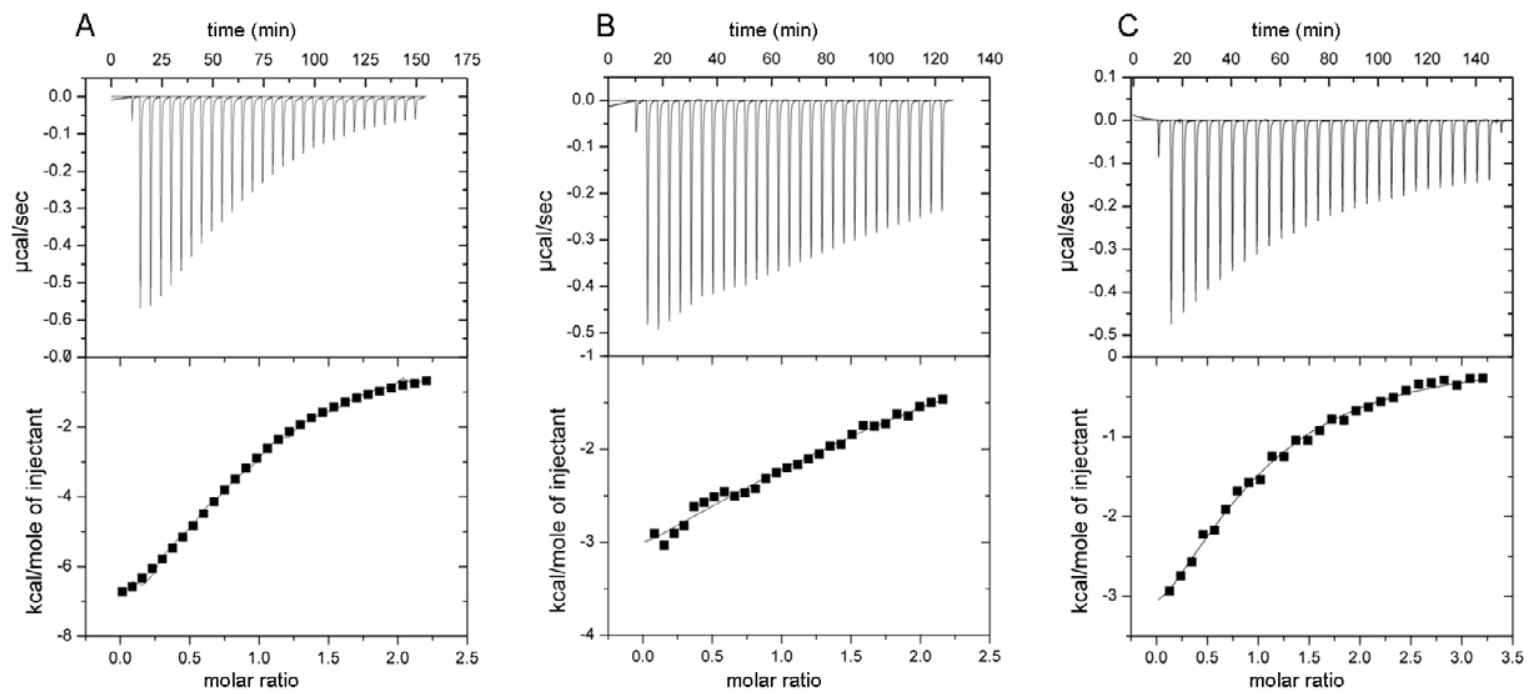

Figure 3 


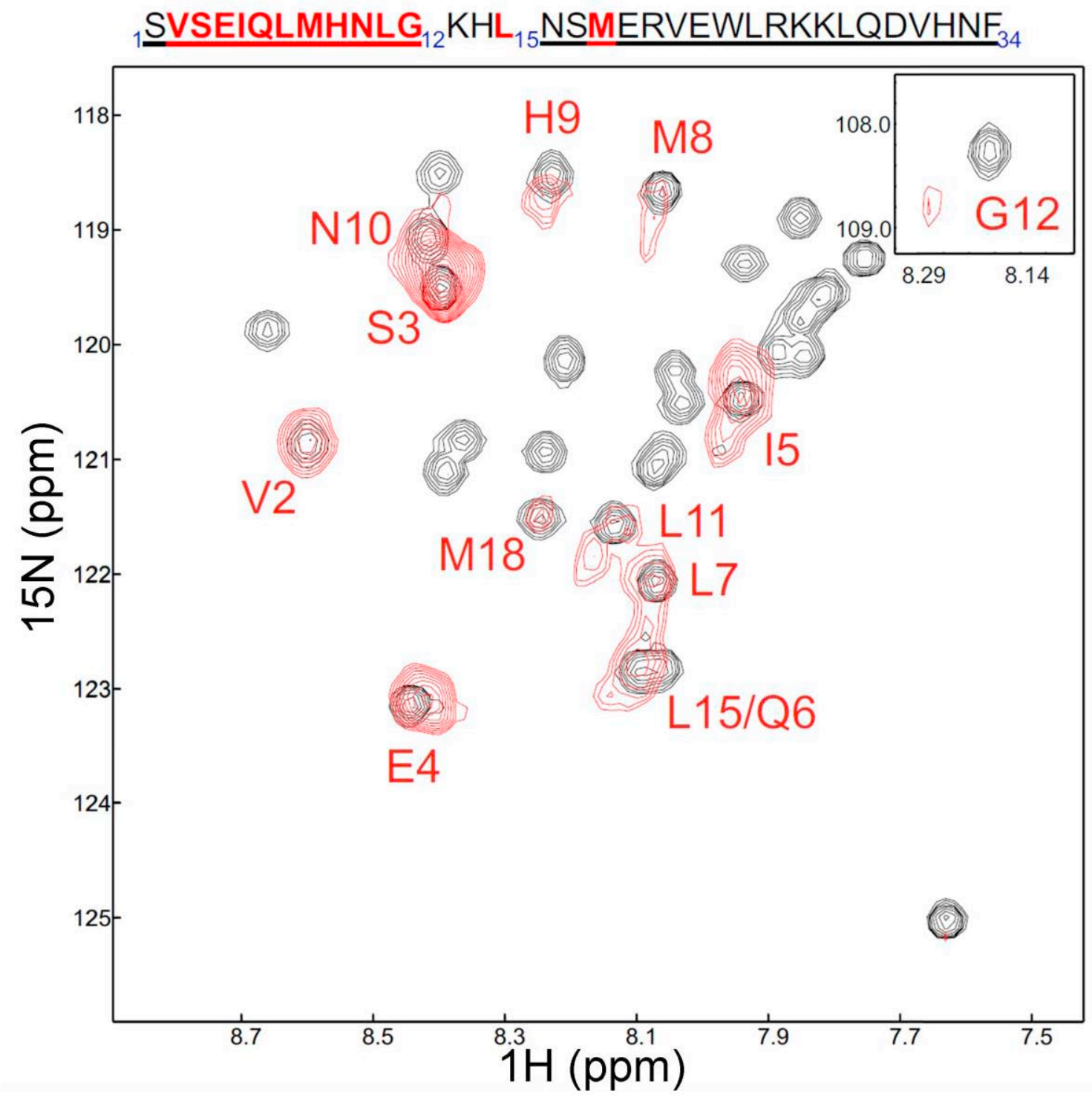

Figure 4 
$A_{116}$

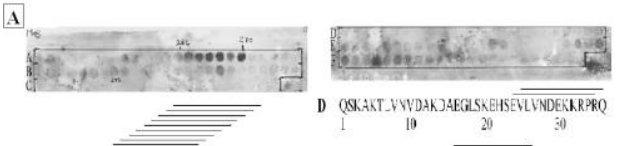

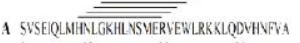

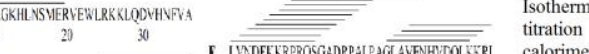
4) 50 (it) calorimetry

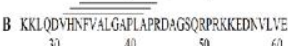

C PXXKEDNLVESHEKSLGEADKADWNITKAKS

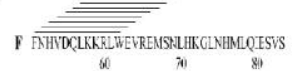

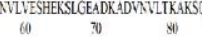

\section{Graphical Abstract}

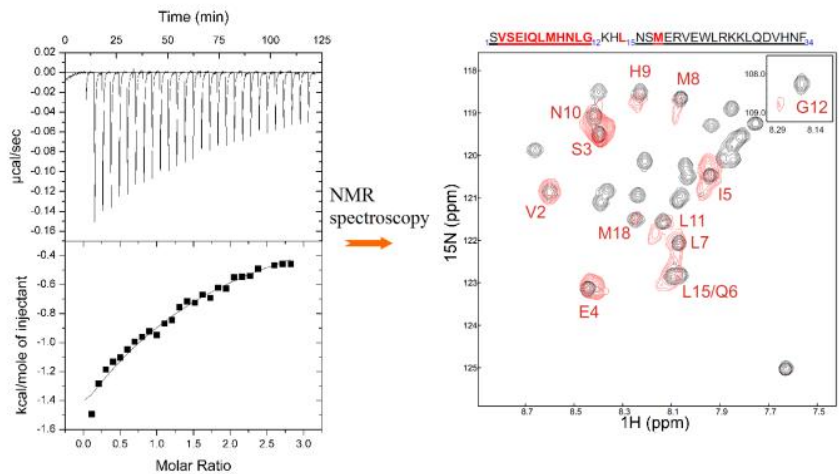


Figure 1. (A) Binding of nPTH1R to PTH peptide libraries. The wildtype (left panel) and reverse (right panel) sequences of PTH (1-84) were presented as peptides of twelve amino acids with a frameshift of one amino acid per spot respectively. To identify binding relevant regions of the PTH peptide sequence the membrane was incubated with refolded nPTH1R. Dark spots represent the regions with bound nPTH1R detected via western blot analysis using a mouse antibody against the ectodomain of PTH1R (Santa Cruz SC12722) and a horseradish peroxidase conjugated goat anti mouse antibody. The sequence of the respective peptide is given below. The amino acid region immobilized on labelled spots is indicated by lines. Line thickness represents strength of binding. (B) Screening of shortened peptide libraries. The peptide sequence of PTH (12-32) was used to create a peptide scanning library covering twelve amino acids with a frameshift of one amino acid. In addition the peptide length was confined from twelve to four amino acids per spot respectively (S1). The peptide library was incubated and analyzed as described. (C) Substitution analysis of peptide libraries. Each amino acid residue of PTH (20-26) was substituted by 19 proteinogenic amino acids necessary to create a peptide library with one amino acid exchange per spot. The substitution peptide library was incubated and analyzed as described above.

Figure 2. Densitometric analysis of substitution peptide library shown in Fig 1C. The data were evaluated by densitometric analysis and it was distinguish between no or strong binding. Substituted residue in (A) Arg20, in (B) Val21 and in (C) Trp23. Increases in binding compared to the exchanged amino acids were evaluated.

Figure 3. Isothermal titration calorimetry during PTH to nPTH1R binding. A solution of (A) $348 \mu \mathrm{M}$ PTH (1-37), (B) $350 \mu \mathrm{M}$ PTH (13-34) and (C) $350 \mu \mathrm{M}$ PTH (1-34) V21Y was titrated stepwise to a solution of $27 \mu \mathrm{M}$ nPTH1R in $50 \mathrm{mM}$ Tris-HCl, $\mathrm{pH} 8$ at $293.15 \mathrm{~K}$. Peak areas from every injection step were integrated and analysed with the ORIGIN software (MicroCal Software, Northhampton, MA, USA). The solid line represents a fit according to the 'one set of sites' binding model. The experiments were carried out in triplicate (Tab.1). 
Figure 4. NMR spectra $\left({ }^{15} \mathrm{~N}-\mathrm{TROSY}-\mathrm{HSQC}\right)$ of free and nPTH1R bound ${ }^{15} \mathrm{~N}-\mathrm{PTH}(1-34)$. Spectra of free $0.75 \mathrm{mM}{ }^{15} \mathrm{~N}-\mathrm{PTH}(1-34)$ (black) and of the ${ }^{15} \mathrm{~N}-\mathrm{PTH}(1-34) / \mathrm{nPTH} 1 \mathrm{R}$ complex (red) at a ration of 1:1.47 were recorded at $298 \mathrm{~K}$ and $600 \mathrm{MHz}$ proton frequency. Red letters in the PTH (1-34) sequence (top) indicate residues, which showed detectable resonances of the ${ }^{15} \mathrm{~N}-\mathrm{PTH}(1-34) / \mathrm{nPTH} 1 \mathrm{R}$ complex. 